\title{
LANDLORDS, TENANTS AND TECHNOLOGICAL INNOVATIONS
}

\author{
Avishay BRAVERMAN* \\ World Bank, Washington, DC 20433, USA \\ Joseph E. STIGLITZ* \\ Princeton University, Princeton, NJ 08544, USA \\ Received October 1984, final version received January 1985
}

\begin{abstract}
There is a long-standing belief that landlords and capitalists have used their control over the means of production to direct the development and adoption of technologies which, ave increased their welfare at the expense of workers. There is also a wide-spread belief that the interlinkage between credit and tenancy markets, which seems so prevalent in LDCs, provides further impetus to the resistance of innovations: innovations which make tenants better off reduce their demand for loans, and thus make landlords (qua creditors) worse-off. These contentions have typically been dismissed out of hand by standard welfare economics arguments. The rural environment of most LDCs may not, however, be adequately described by the standard economic model on which this welfare analysis is based. In particular, in many LDCs sharecropping contracts are widely employed; there is evidence of widespread unemployment, and there is not the full set of (risk and capital) markets required by the competitive paradigm. The objective of this paper is to show under quite general conditions that the institutional structure of the economy may indeed be an important determinant of whether a particular innovation will or will not be adopted. We show that:

(i) landlords may wish to - and can - resist innovations which unambiguously increase production whenever sharecropping contracts are employed,

(ii) conversely, landlords may adopt innovations which not only lower the welfare of workers, but even lower net national product,

(iii) the presence of interlinkage may, indeed, affect the adoption of a new technology; however, the reason for this is only partly related to the effect of innovations on tenants' borrowing. Indeed, we show that innovations may increase as well as decrease the tenants' demand for borrowing.
\end{abstract}

\section{Introduction}

There is a long-standing belief that landlords and capitalists have used their control over the means of production to direct the development and

*The views expressed are those of the authors and do not necessarily reflect those of their affiliated organizations. We thank David Newbery, T.N. Srinivasan, Russ Krelove, In-Koo Cho, Erika Jorgensen, anonymous referees, and in particular $\mathrm{D}$. Abreu for many helpful comments on earlier drafts of this paper. An earlier version of this paper was presented to the European Congress of the Econometric Society in Pisa, Italy, 1983. 
adoption of technologies which have increased their welfare at the expense of workers. Although workers may be better-off than they used to be, they are not as well-off as they might have been had they assumed control of the innovation process.

There is also a widespread belief that the interlinkage between credit and tenancy markets, ${ }^{1}$ which seems so prevalent in LDCs, provides further impetus to the resistance of innovations: innovations which make tenants better-off reduce their demand for loans, and thus make landlords (qua creditors) worse-off. ${ }^{2}$

These contentions have typically been dismissed out of hand by standard welfare economics arguments. An innovation is defined as a shift outward in the production possibilities schedule, or equivalently, as an outward shift in the utility possibilities schedule. Then, if the economy is competitive, at the old equilibrium level of utility of workers, it pays each landlord to adopt the innovation. In doing so, landlords may increase their demand for tenants, and as a result, in the new equilibrium, they may be worse-off. Still, it is in the interest of each competitive landlord to adopt the innovation. Alternatively, if the landlords act collusively, say as a single monopsonist, they will push the tenants to the subsistence level. Again, it will always pay them to adopt the innovation. Thus, while in a perfect monopoly, innovations are never disadvantageous to an individual landlord; in perfectly competitive environments, innovations advantageous to an individual landlord, which when the general equilibrium effects are taken into account are disadvantageous to landlords as a group, cannot be effectively resisted.

The rural environment of most LDCs may not, however, be adequately described by the standard economic model on which this welfare analysis is based. In particular, in many LDCs, sharecropping contracts are widely employed; there is evidence of widespread unemployment, and there is not

\footnotetext{
'For an excellent survey of the phenomena of interlinked markets, see Bardhan (1980) and also Binswanger and Rosenzweig (1984). Elsewhere, we provide an economic rationale for interlinkage, derived from the general theory of moral hazard [Braverman-Stiglitz (1982)]. For other theoretical discussions of interlinkage, see Bell-Zusman (1980), Braverman-Srinivasan (1981), Braverman-Guasch (1984) and Mitra (1983).

${ }^{2}$ See, for instance, Bhaduri $(1973,1979)$. Bhaduri, noting the interlinkage between credit, land and labor markets to which we referred earlier, has argued that landlords resist innovations because these typically reduce the demand for tenants' credit, and hence landlords' profits. Newbery (1975), Braverman-Stiglitz (1982) and Mitra (1983) have questioned the exploitation explanation for interlinkage that Bhaduri has put forward. Srinivasan (1979), using Bhaduri's model, has argued against Bhaduri's contention that innovations lead to lesser demand for credit. As we show below the demand for credit may either increase or decrease as a result of an innovation, but whether landlords are better- or worse-off as a result of an innovation does not depend solely on the effect of the innovation on the demand for credit. A decrease in tenants' demand for credit is neither necessary nor sufficient for landlords to resist innovations. Newbery (1975) called attention to the need to focus on moral hazard issues in analyzing resistance to technological innovations. He provided an example in which technological innovation would be resisted by monopsonist landlords.
} 
the full set of (risk and capital) markets required by the competitive paradigm. ${ }^{3}$

The objective of this paper is to show under quite general conditions that the institutional structure of the economy may indeed be an important determinant of whether a particular innovation will or will not be adopted. ${ }^{4}$ We show that:

(i) landlords may wish to - and can - resist innovations which unambiguously increase production whenever sharecropping contracts are employed,

(ii) conversely, landlords may adopt innovations which not only lower the welfare of workers, but even lower net national product,

(iii) the presence of interlinkage may, indeed, affect the adoption of a new technology; however, the reason for this is only partly related to the effect of innovations on tenants' borrowing. Indeed, we show that innovations may increase as well as decrease the tenants' demand for borrowing.

- Though widespread unemployment is common in many LDCs, we do not address this fact here. In a sequel to this paper [Braverman-Stiglitz (1985)] we argue that the mere presence of unemployment (even under a pure wage system) may be sufficient to generate resistance by landlords and employers to the adoption of superior technological innovations.

\section{Sharecropping and the adoption of technological innovations}

Traditional welfare analysis has equated an outward shift in the production possibilities schedule with an outward shift in the utilities possibilities schedule. Under traditional economic assumptions, the two are, in fact, equivalent. But whenever factors do not get paid their full marginal product, the two may not be equivalent. Such is the case with sharecropping contracts. ${ }^{5}$ The change in technology may increase output for each level of

\footnotetext{
${ }^{3}$ The impact of innovations on the marginal costs of landlords and on the utilities of tenants and landlords has also been analyzed in the context of the economic history of the U.S. rural South; e.g., Reid (1976) and Alston (1983) discuss the impact of technology on southern landlords' attitude towards sharecropping.

${ }^{4}$ For most of the analysis, we do not discuss the costs of innovation. We envisage an invention which has occurred and ask under what conditions will the invention be adopted. It is straightforward to modify our analysis to take account of the costs of innovation, provided we have a well-defined theory of how those costs are to be shared.

${ }^{5}$ The contract need not be a pure sharecropping contract; there may, for instance, be a fixed rent or wage component to the tenancy agreement. It should be clear that the argument applies to any principal-agent problem in which the principal (e.g., landlord) bears some of the risk and hence the agent (e.g., tenant) does not bear the full consequences of his actions.
} 
input; but at the same time, it may exacerbate the incentive problem. As a result, even a competitive landlord may not wish to adopt the innovation.

The objective of this paper is to identify circumstances in which, with sharecropping, innovations (in the technological sense) will not be adopted.

The analysis is divided into two stages:

(i) Fixed contract. Under what conditions will landlords be worse-off when the terms of the contract between the landlord and tenant remain unchanged? The answer to this question determines whether, if landlords could resist an innovation, they would do so if the terms of the contract could not be altered (e.g., if they were fixed by social norms).

(ii) Variable contracts; fixed expected utility. The terms of the contract may, of course, change. The standard formulation of the competitive equilibrium with sharecropping [e.g., Stiglitz (1974)] has the terms of the contract chosen to maximize the expected utility of the landlord, given a level of expected utility of the tenant. ${ }^{6}$ The change in the technology will thus induce a change in the terms of the contract, and the question is, when these adjustments are taken into account, under what conditions will landlords still be worse-off? The conditions derived in this section are important, because they not only determine when innovations will not be adopted in competitive environments, but they also show when innovations will not be adopted under noncompetitive conditions. A monopsony landlord may be modelled as maximizing his expected utility, subject to the subsistence constraint of his workers.

\section{Partial vs. general equilibrium analysis}

It is important to emphasize that even if landlords do not resist innovations, i.e., each believes that his expected utility will be increased by its adoption, in the general equilibrium, landlords may be worse-off. Under these circumstances, collusion may be required for landlords to resist innovation. In small villages with few landlords the possibility of collusion (tacit or explicit) is very plausible [e.g., Rudra (1982)]. This collusion may be enforced by a variety of social and economic sanctions [see Akerlof (1980)]. The conditions under which landlords will voluntarily adopt disadvantageous innovations are discussed in subsection 2.4 below. The possibility of such innovations has, of course, long been recognized [see, e.g., Hicks (1963)]. What distinguishes our analysis from Hicks' is that we emphasize the implications of imperfect supervision technology and limited risk markets on the general equilibrium effects. Hicks deals only with perfectly competitive and perfectly monitored wage labor markets. Whether landlords can restrict the adoption of a new technique depends also on whether the tenants' use of

\footnotetext{
${ }^{6}$ The landlord is an 'expected utility' taker, rather than a price (wage) taker.
} 
the technique can be observed, and, if so, whether the contractual arrangements between the landlord and tenant allow the landlords to specify what technologies the tenant may employ.

Before using calculus we present a simple example illustrating why, with sharecropping, innovations may not be adopted.

\subsection{An example}

To make the example as simple as possible, we ignore uncertainty and, initially, assume that the terms of the contract are fixed. ${ }^{7}$

Consider the technological change represented in figs. 1a and $1 \mathrm{~b}$. In the old technique, denoted by $f(e)$, the marginal return to effort was very high up to $e^{*}$, and that is the level of effort supplied by the tenant. The new technology, denoted by $\hat{f}(e)$, though unambigously better than the old, has diminishing returns set in at a much lower level of effort and at a lower level of output. The tenant now operates at $e^{* *}$. As a result, the landlord is worseoff. This is true even when the share of the tenant, $\alpha$, is lowered to leave the tenant just as well-off as before (see fig. $1 \mathrm{~b}$ ).$^{8}$ Landlords, in this case, would like to restrict the adoption of the new technique. Note that no collusive action is required and in the particular instance drawn in figs. 1a and $1 \mathrm{~b}$, national output is increased by this resistance to new technology, at the expense of tenants' welfare. ${ }^{9}$

This example shows that there may be improvements to the land which increase tenants' productivity but lower the net returns to land. These would clearly not be adopted by landlords. They would be if tenants owned their own land. Tenants might even be willing to pay for the improvements themselves, if their tenure on a particular plot of land was secure, but not otherwise, (and the latter seems to be the prevalent situation in many LDCs). ${ }^{10}$

\subsection{A general argument: Fixed contract}

More generally, with a sharecropping contract, the tenant's problem is

$$
\max _{\{e\}} \mathrm{E} U(\alpha f(e, T, \Omega, \theta), e) \equiv V(\Omega ; \alpha, T)
$$

${ }^{7}$ In the absence of uncertainty, it is hard to justify the employment of sharecropping relationships, so long as effort is variable. This assumption is employed to simplify the exposition; as the discussion below makes clear, nothing critical depends on this assumption.

${ }^{8}$ Other terms of the contract (such as plot size) might also adjust. See, e.g., Stiglitz (1974), Newbery-Stiglitz (1979), Braverman-Srinivasan (1981), Braverman-Stiglitz (1982) and the discussion below.

${ }^{9}$ Ordinary national product measures evaluate only output and do not include effort evaluation which enters the tenant's utility.

${ }^{10}$ Alternatively, our analysis can be interpreted as showing that there is an important set of 'welfare' enhancing innovations which it would never pay landlords to adopt. 


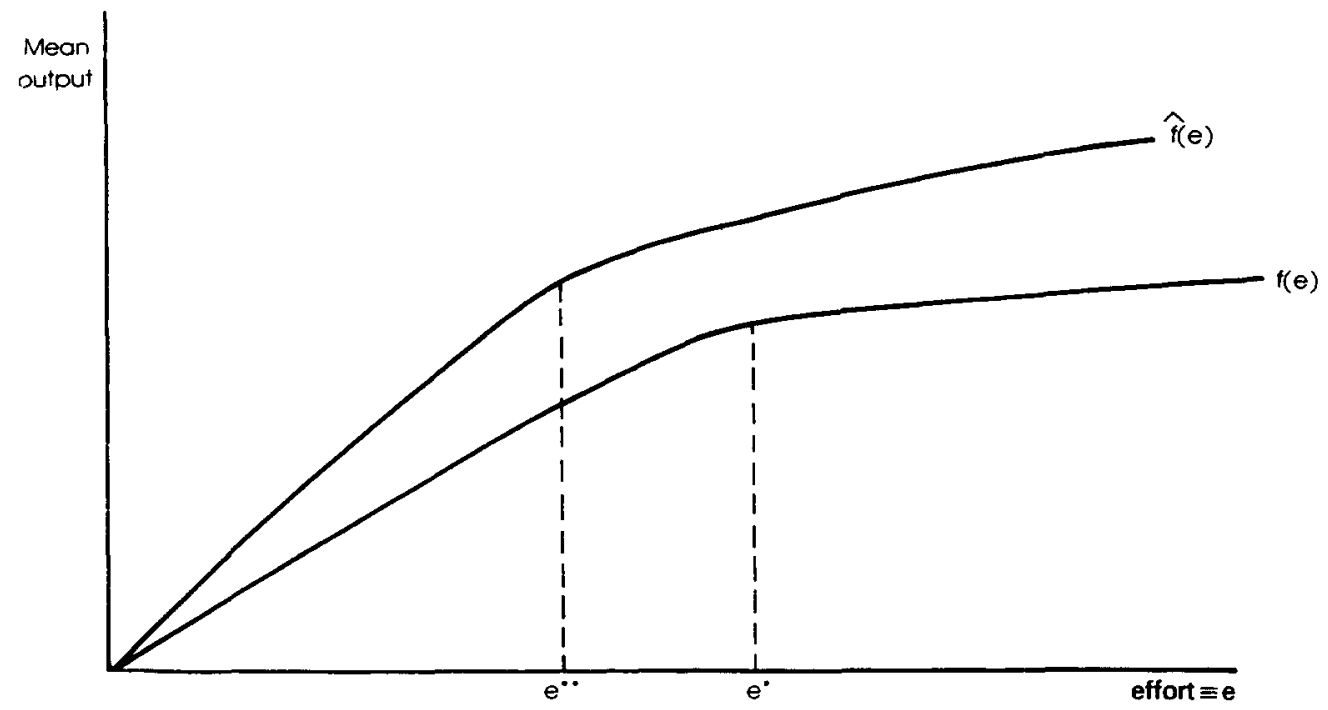

Fig. 1a. Comparison of the new technology, $\hat{f}$, with the old one, $f$.

$$
(1-\widehat{\alpha}) f\left(e^{*}\right)<(1-\widehat{\alpha}) f\left(e^{*}\right) \operatorname{or} \hat{\alpha}=1-(1-\alpha) \frac{f\left(e^{*}\right)}{\left.\hat{R} e^{*}\right)}
$$

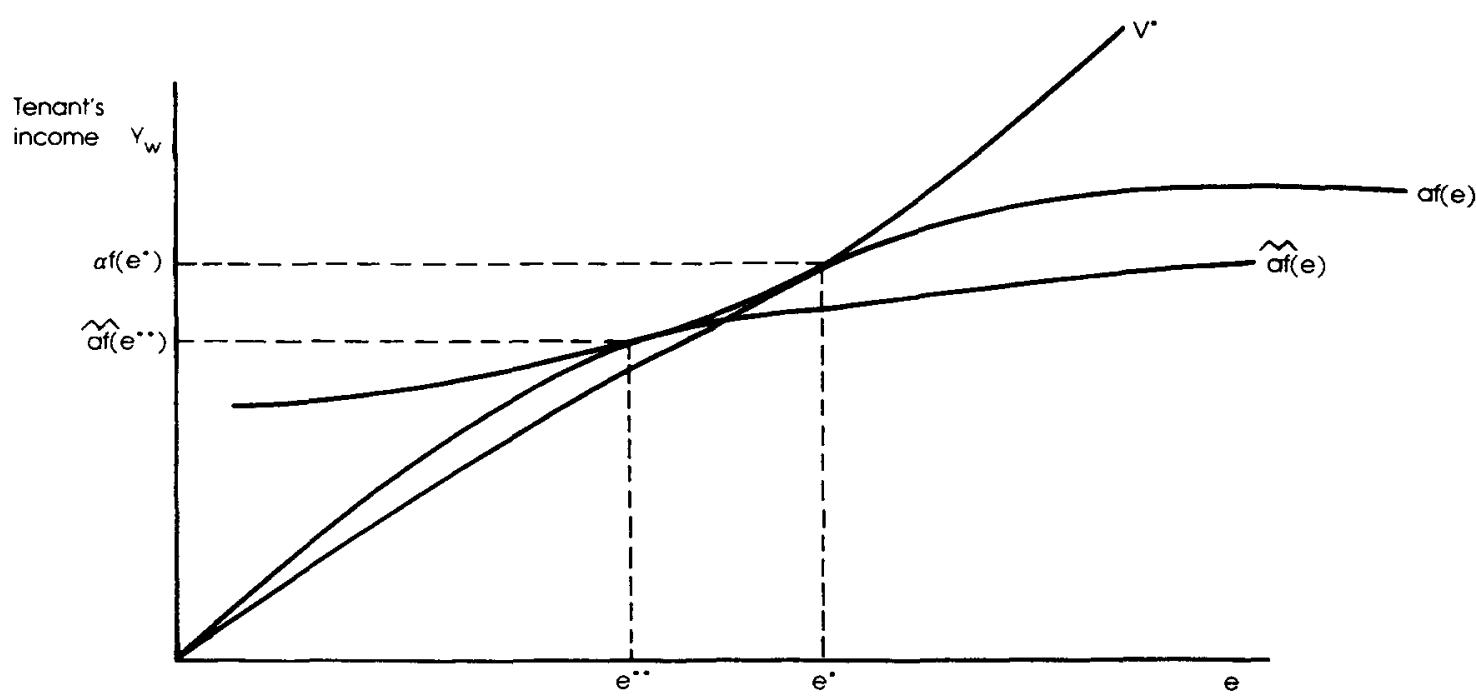

World Bank-27163

Fig. 1b. Tenant's choice of effort under the old and new (adjusted) share contracts; ( $\alpha$ and $\hat{x}$, respectively), for a given level of expected utility $V^{*}$. Note that if the tenant is to be indifferent, $\alpha>\hat{\alpha}$, where if the landlord is worse-off

$$
(1-\hat{\alpha}) f\left(e^{* *}\right)<(1-\hat{\alpha}) f\left(e^{*}\right) \quad \text { or } \quad \hat{a}>1-(1-\alpha)\left(f\left(e^{*}\right) / \hat{f}\left(e^{* *}\right)\right) \text {. }
$$


where $\alpha=$ share of tenant, $T=$ plot size, $e=$ tenant's effort, ${ }^{11} f=$ (value of) output $^{12}$ in state $\theta$ with technology $\Omega$, effort $e$, and plot size $T$, and $U=U\left(Y^{w}, e\right)$ is the tenant's utility function, which depends on his income, $Y^{w}=\alpha f$, and his effort, $e$, with the usual properties. ${ }^{13}$

The equilibrium contract is described by $\{\alpha, T\}$.

The landlord is assumed to be sufficiently wealthy and provided with a sufficient number of alternatives to diversify his risk portfolio, so that he can be represented as risk-neutral; he maximizes his expected income,

$$
\pi \equiv(1-\alpha) \mathrm{E} f .
$$

We shall be concerned with changes in technology which, in a purely technological sense, are unambiguous improvements, i.e.,

$$
f_{\Omega}>0 \text { for all } \theta, e \text { and } T \text {. }
$$

In every state of nature, for any pre-specified level of effort and plot size, output is higher with the new technology than with the old, so that the new technology - in a technological sense - dominates the old. It is obvious that for such technologies, with a fixed contract, tenants are unambiguously better-off, i.e.,

$$
\frac{i V(\Omega ; \alpha, T)}{\partial \Omega}>0
$$

Straightforward differentiation of landlord profits shows that

$$
\frac{\partial \pi}{\partial \Omega}=\frac{\partial(1-\alpha) \mathrm{E} f}{\partial \Omega}=(1-\alpha)\left(\mathrm{E} f_{\Omega}+\mathrm{E} f_{e} \frac{\partial e}{\partial \Omega}\right),
$$

and landlords will resist the innovation if

$$
\left|\frac{\partial e}{\partial \Omega}\right|>\frac{\mathrm{E} f_{\Omega}}{\mathrm{E} f_{e}} \cdot
$$

" $e$ can represent a vector of inputs of the tenant.

${ }^{12}$ For most of the analysis we assume that the price of output of agricultural goods is fixed. Hence, we let it be equal to unity, and $f$ becomes physical output.

${ }^{13} U_{Y}>0, U_{Y Y}<0, U_{e}<0, U_{e e}<0, U$ is a quasi-concave.

${ }^{14}$ This formulation assumes that the effort decision is made before $\theta$ is known. If it is made after $\theta$ is known, coindition (5) becomes

$$
\mathrm{E} \frac{\mathrm{f}_{e}}{\mathrm{E} f_{e}} \frac{\partial e}{\partial \Omega}>\frac{\mathrm{E} f_{\Omega}}{\mathrm{E} f_{e}}
$$

i.e., the weighted average effort response must be greater than some critical amount. 
With a sufficiently large negative effort response on the part of tenants, landlords will be worse-off at the old contract, and thus resist the innovation.

The magnitude of $\partial e / \partial \Omega$ depends both on the properties of the tenant's utility function and on how the innovation changes the technology. For instance, if the utility function is separable of the form

$$
U=u\left(Y^{w}\right)-v(e)
$$

then ${ }^{15}$

$$
\left.\frac{1}{e}\left(\frac{\partial e}{\partial \Omega}\right)\right|_{\alpha}=\frac{\left\{\operatorname{Em}\left(f_{e \Omega} / f_{e}\right)-R\left(f_{\Omega} / f\right)\right\}}{\gamma+\operatorname{Em}\{R \alpha-\eta\}}
$$

where

$$
m \equiv u^{\prime} f_{e} \mid \mathrm{E} u^{\prime} f_{e}, \quad \alpha \equiv f_{e} e / f, \quad \eta \equiv f_{e e} e / f_{e}
$$

$\gamma \equiv v^{\prime \prime} e / v^{\prime}$ denotes the elasticity of the marginal disutility of effort and $R \equiv$ $-u^{\prime \prime} Y^{w^{\prime}} / u^{\prime}$ denotes the measure of relative risk aversion. The effect on effort depends not only on how the innovation affects output, $f_{\Omega}$, but also on how the innovation affects the marginal return to effort, $f_{e \Omega}$, as our earlier example illustrated. ${ }^{16}$ There are, as usual, two effects: an income effect, which if leisure is normal leads to a reduction in effort, and is greater the greater is the individual's risk aversion, $R$, and the greater is the proportionate upward shift in the production function, $f_{\Omega} / f$; and a substitution effect, which can be of either sign. If the innovation reduces the marginal product of effort (as in our example), i.e., $f_{e \Omega}<0$, then this too leads to a reduction in effort. Thus, landlords resist an innovation if it reduces the marginal return to effort by a sufficiently large amount. ${ }^{17}$

We now show that landlords will adopt an innovation if and only if it increases national income (taking into account the effort response of tenants).

${ }^{15}$ This follows by differentiating the tenant's first order condition for effort, $\alpha \mathrm{E} u f_{e}=v^{\prime}$.

${ }^{16}$ Note that the denominator of $(8)$ is always positive from the second order condition.

${ }^{17}$ Alternative sufficient conditions for the landlord to resist innovation can also be derived. As $R$ becomes large,

$$
\frac{\partial \mathrm{e}}{\partial \Omega} \approx \frac{-\mathrm{E} \psi f_{\Omega} / f}{\mathrm{E} \psi f_{e} / f} \quad \text { where } \psi \equiv R u^{\prime} f_{e}
$$

Thus, if $f=h(\theta) g(e, T, \Omega)$, then

$$
\frac{\partial e}{\partial \Omega} \approx \frac{-f_{\Omega}}{f_{e}},
$$

and the landlord is indifferent to the innovation. If $R$ is constant, and $f=h(\theta, T, \Omega) Z(e)$, then the innovation lowers landlord's welfare if

$$
\mathrm{E} \frac{h_{\Omega} u^{\prime} f_{e} / h}{E u^{\prime} f_{e}}>\frac{E h_{\Omega}}{E h},
$$

e.g., if $h h_{\Omega g} / h_{\Omega} h_{\theta}<R$. 
The effect of an innovation on national income is simply given by

$$
\mathrm{E}\left(f_{\Omega}+f_{e} \frac{\partial e}{\partial \Omega}\right)
$$

But this coincides precisely with condition (6), and the result is immediate. (Note that the level of landlord's share, $1-\alpha$, affects the innovation adoption only indirectly.)

At the same time, it is apparent that landlords resist innovations which may decrease their welfare only slightly, but increase that of tenants enormously; if the adoption of the innovation were controlled by a government which maximizes national welfare, such innovations would be adopted, provided some weight is attached to the gain of tenants. ${ }^{18}$

\subsection{Landlord's profits at fixed expected utility of tenants}

The argument above establishes that if the terms of the contract are fixed by law or custom (as they often are), ${ }^{19}$ then, in the short run, landlords will resist the innovation, until appropriate adjustments can be made to the contract.

The relevant question for the longer run analysis, where the terms of the contract are adjustable, is whether, when the terms of the contract are adjusted to leave tenants indifferent, will landlords be better-off. We established earlier that at the old terms, innovations always make tenants better-off. Hence, if the expected utility of tenants is to remain unchanged, the share of tenants or the plot size must be lowered. The change in technology then has three effects on landlords: (a) the direct effect of an increase in output, which increases landlords' income, (b) the direct effect of the adjustment in the contract, which will make landlords better-off, and (c) the effect of the adjustment of effort both to the change in technology and to the compensating adjustment in the contract. This is of ambiguous sign, the 'substitution' effect from the lower share leads to lower levels of effort while the change in technology itself may increase the marginal return to effort. Since the landlord always adjusts the terms of the contract in such a way that the total effect of the adjustment is to make himself better-off, the landlord is less likely to resist innovations if he is able to adjust the terms of the contract than if he is not.

\footnotetext{
${ }^{18}$ Since the terms of the contract are fixed, landlords will resist the adoption of some innovations which would be Pareto improvements if the terms of the contract could be adjusted, e.g., if lump sum transfer payments may be made between workers and landlords.

${ }^{19}$ Output shares in LDCs are often found to be fixed at 50:50.
} 
Analytically, instead of (5) we obtain

$$
\begin{aligned}
& \left.\frac{d \pi}{\mathrm{d} \Omega}\right|_{\bar{V}}=\mathrm{E}\left\{(1-\alpha)\left[f_{\Omega}+\left.f_{T} \frac{\mathrm{d} T}{\mathrm{~d} \Omega}\right|_{\bar{V}}\right]-\left.f \frac{\mathrm{d} \alpha}{\mathrm{d} \Omega}\right|_{\bar{V}}+\left.(1-\alpha) f_{e} \frac{\mathrm{d} e}{\mathrm{~d} \Omega}\right|_{\bar{V}}\right\} . \\
& \begin{array}{lll}
\begin{array}{l}
\text { Direct } \\
\text { effect of }
\end{array} & \begin{array}{l}
\text { Direct effect } \\
\text { of change of }
\end{array} & \begin{array}{l}
\text { Effect of } \\
\text { change in }
\end{array} \\
\text { technology } & \text { contract } & \text { effort }
\end{array}
\end{aligned}
$$

The general derivation of $\mathrm{d} \alpha /\left.\mathrm{d} \Omega\right|_{\bar{v}}, \mathrm{~d} T /\left.\mathrm{d} \Omega\right|_{\bar{v}}$ and $\mathrm{d} e /\left.\mathrm{d} \Omega\right|_{\bar{v}}$ is complicated. For our present purpose, we limit ourselves to the special case where technology is such that there is an 'efficient' plot size which remains unaltered by the change in $\Omega,{ }^{20}$ and where utility is separable. Then,

$$
\left.\frac{\mathrm{d} \alpha}{\mathrm{d} \Omega}\right|_{\bar{v}}=-\frac{\alpha \mathrm{E} u^{\prime} f_{\Omega}}{\mathrm{E} u^{\prime} f}<0
$$

and

$$
\begin{aligned}
\left.\frac{\mathrm{d} e}{\mathrm{~d} \Omega}\right|_{\bar{v}} & =\frac{\partial e}{\partial \Omega}+\left.\frac{\partial e}{\partial \alpha} \frac{\mathrm{d} \alpha}{\mathrm{d} \Omega}\right|_{\bar{v}} \\
& =\frac{x\left[\left(\mathrm{E} u^{\prime \prime} f_{\Omega} f_{e}^{\alpha}+u^{\prime} f_{e \Omega}\right)-\left(\mathrm{E} u^{\prime} f_{\Omega} / \mathrm{E} u^{\prime} f\right) \cdot \mathrm{E}\left(u^{\prime}+\alpha u^{\prime \prime} f\right) f_{e}\right]}{v^{\prime \prime}-\alpha \mathrm{E}\left\{u^{\prime \prime} f_{e}^{2} \alpha+u^{\prime} f_{e e}\right\}} .
\end{aligned}
$$

It is clear that there are changes in technology which have a large effect (locally) on the marginal return to effort ( $f_{e \Omega}$ is large) but which at the same time, have a small (positive) effect on output ( $f_{\Omega}$ is small). These changes will thus induce a larger reduction in effort, cause only a small adjustment in the terms of the contract (note that $\mathrm{d} \alpha / \mathrm{d} \Omega$ depends only on the magnitude of $f_{\Omega}$, not on $f_{e \Omega}$ ), and hence make landlords unambiguously worse-off. This is precisely the case depicted earlier in fig. $1 \mathrm{~b}$.

It should be noted that nowhere in the analysis so far have we made use of the competitive hypothesis. Hence our analysis is equally applicable to the

$$
\begin{aligned}
& { }^{20} \text { Formally, the optimal contract is the solution to the problem } \\
& \qquad \operatorname{Max}(1-x) \mathrm{E} f[e(x, T, \Omega), T, \Omega, 0] \quad \text { s.t. } \quad V(\Omega ; \alpha, T) \geqq \bar{V}
\end{aligned}
$$

i.e., $\{\alpha, T\}$ solves the following pair of equations:

$$
-\mathrm{E} f+(1-\alpha)\left[\mathrm{E} f_{e} \frac{\partial e}{\partial \alpha}-\left(f_{c} \frac{\hat{i} e}{\partial T}+f_{T}\right) \frac{V_{a}}{V_{T}}\right]=0
$$

and

$$
V(\Omega ; \alpha, T)=\bar{V} .
$$

$\mathrm{d} \alpha / \mathrm{d} \Omega$ and $\mathrm{d} T / \mathrm{d} \Omega$ are found by straightforward implicit differentiation of (i) and (ii). 
competitive landlord who takes as given the expected utility which his contract must provide to tenants (in order to obtain tenants) as it does to monopsonist landlords, who push their tenants down to the subsistence expected utility level.

In this section we have established that when there are incentive problems (as arise in the context of sharecropping), an innovation which unambiguously increases output for each level of input may yet shift a segment of the utility possibilities schedule inward, i.e., at certain prespecified levels of expected utility of tenants, landlords are worse-off. In fig. 2 and 3 we provide two such examples. In the first example (fig. 2), the whole utility possibilities frontier shifts inward due to the new innovation. Therefore, the innovation will be rejected, both by a monopsonist landlord, who drives the workers down to their subsistence level, and in a competitive equilibrium.

Perhaps more interesting is the second example (fig. 3) where the new utility possibilities schedule crosses the old. In the case illustrated this innovation will be rejected by the monopsonist, but would be adopted in the competitive environment.

Finally, we note that in contrast to the results of section 2.2 [compare (10) to (5) and (9)], if the terms of the contract are adjustable, the decision of the landlord to adopt an innovation does not coincide with whether the innovation increases national income (taking into account the adjustment of the terms of the contract). There are innovations which lower national income but which still will be adopted (because they enable the landlord to lower the share received by workers).

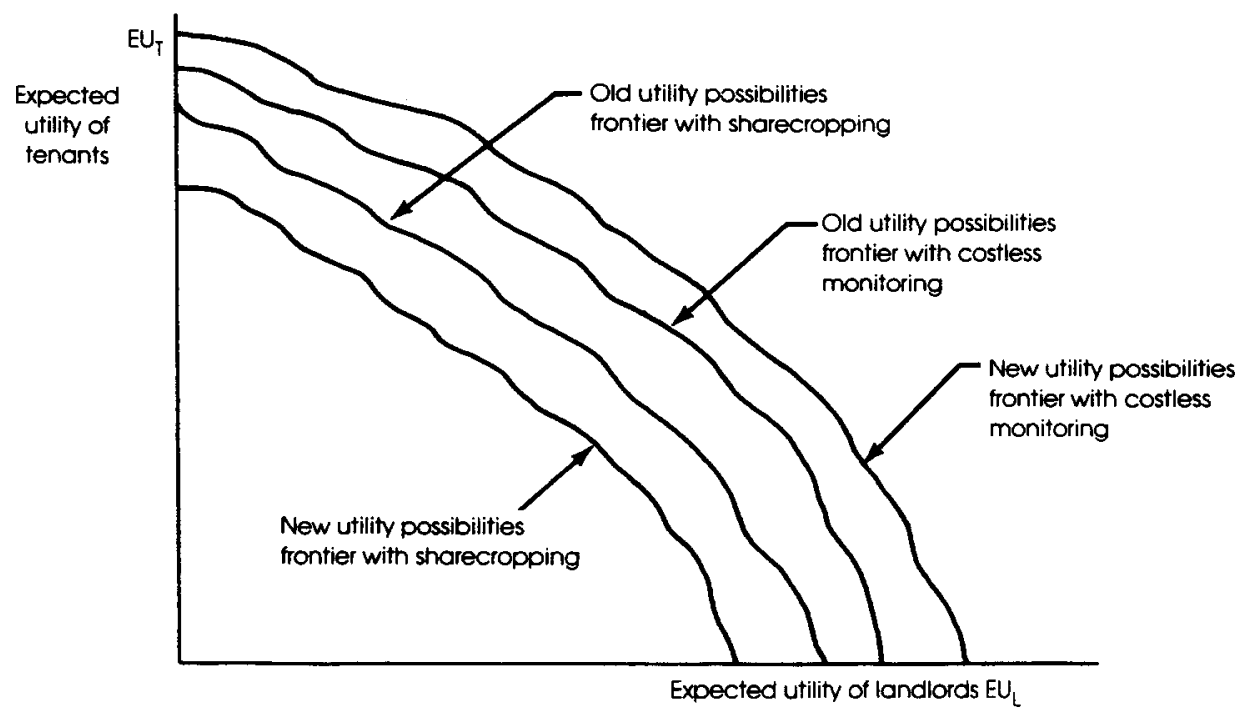

Fig. 2. A case in which innovation under sharecropping shifts the whole utility possibilities frontiers inward. 


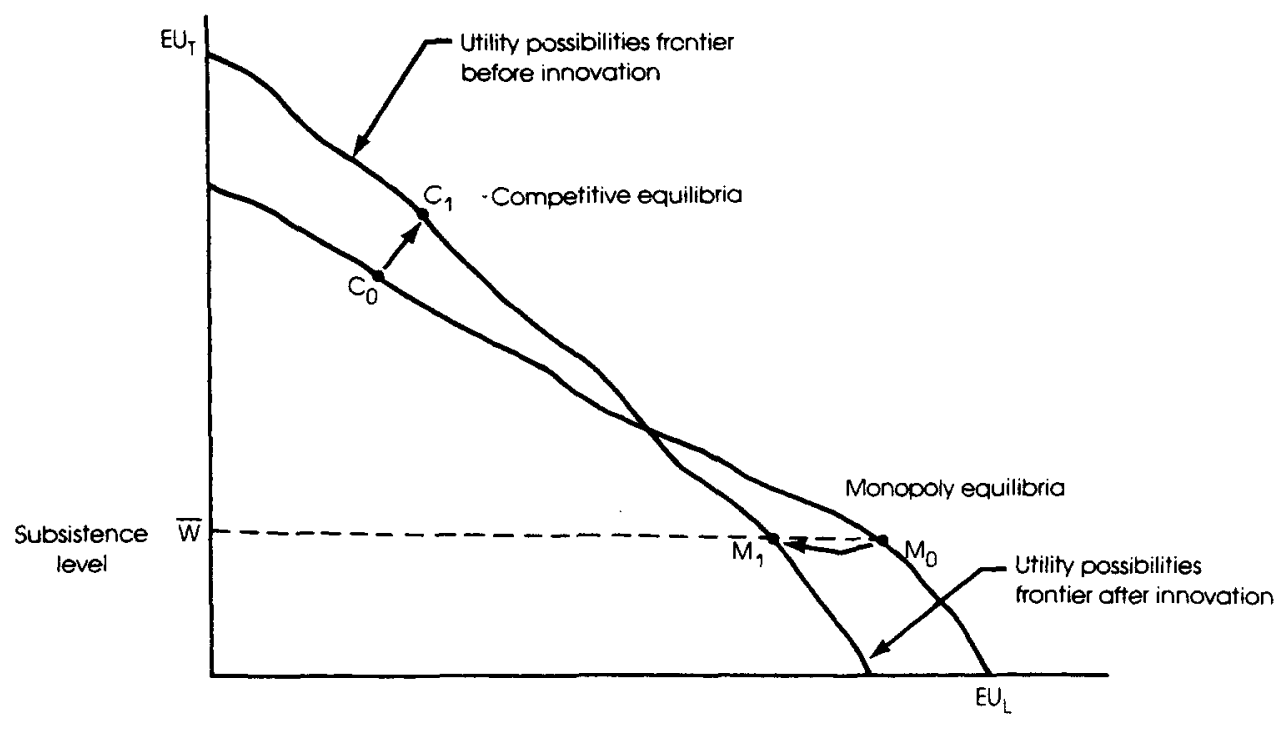

World Bonk -27164

Fig. 3. A case in which the utility possibilities frontiers cross; monopolist resists innovation which is adopted in competitive economy.

\subsection{General equilibrium impact of innovation}

The fact that a landlord finds it in his interest to adopt the innovation in a competitive economy (where the landlord takes the level of expected utility of tenants as given) does not mean that when all landlords adopt the innovation, landlords will be better-off. How the gains to an innovation are distributed between the landlords and tenants, in equilibrium, will depend on how the innovation affects the demand for tenants, or, equivalently, how the innovation affects the equilibrium plot size. If at the old level of expected utility of tenants, the optimal plot size is increased, then demand for tenants will decrease, and tenants will be worse-off with the innovation; ${ }^{21}$ all the gains accrue to the landlords; if, in contrast, at the old level of expected income (utility) of landlords, the optimal plot size is reduced, then landlords will be worse-off with the innovation. However, in a competitive environment, although they might wish to resist the innovation, they can only do so through collusive actions. Hence it will pay each landlord to adopt the new technology.

The conditions under which an innovation will lead to an increase in the demand for labor (smaller plot sizes) may be derived as a straightforward

\footnotetext{
${ }^{21}$ This assumes that the supply of tenants is not perfectly elastic. If the supply is perfectly elastic, clearly, $\vec{V}$ remains unchanged, and the partial equilibrium and general equilibrium effects coincide. The change in plot size simply affects the number of tenant farmers [see BravermanSrinivasan (1981) for such a model].
} 
extension of the analysis of Braverman-Stiglitz (1982). For our purposes, it is sufficient to note that a critical determinant of the effect of the innovation on plot size is the magnitude of $f_{T \Omega}$, i.e., whether the innovation increases or decreases the marginal return to (larger) plot size: while in the traditional analysis the sign of $f_{T \Omega}$ would be the sole determinant of the general equilibrium impact of the innovation on landlords, here the general equilibrium effect depends as well on how the innovation affects the marginal return to effort and the share compensated effort response from a change in plot size, i.e., the technology of supervision and the contractual framework are also critical in assessing the general equilibrium effects.

\section{Interlinkage and the adoption of innovations}

In this section, we address the question of whether the fact that landlords are frequently also lenders to their tenants makes it more or less likely that landlords will wish, or be able, to resist innovations. It has, for instance, been argued [Bhaduri (1973)] that increases in the income of tenants will reduce their need for borrowing; since the landlord-cum-lenders make high rates of return on their loans, this will lower their profits. Landlord-cum-lenders will, it is thus argued, resist innovations. Srinivasan (1979), on the other hand, has demonstrated that Bhaduri's results require that loans be inferior goods. If they are normal, an increase in income on the part of tenants will increase the demand for loans, and this will increase the income of the landlord-cumlenders.

We argue here that the conclusion - that interlinkage of credit and tenancy markets (like other important aspects of the institutional organization of agriculture) has an important effect on innovation - is correct, but the lines of argument by which earlier studies reached that conclusion are either incorrect, or incomplete. In particular, we shall show:

(i) The earlier analyses of the effect of technological change on borrowing, though correct in noting that changes in technology could have a significant effect on borrowing by tenants, improperly treated the demand for loans by ignoring uncertainty; in contrast, we argue that the demand for loans which is a derived demand and which depends on the relationship between present and future income, is critically affected by the stochastic properties of future income. Thus, under quite plausible assumptions concerning the nature of the utility functions of tenants and the nature of the innovation, innovations may either increase or decrease the demand for borrowing. The basic line of the argument is provided below, while mathematical demonstration of sufficient conditions for results in both directions are presented in our earlier working paper [Braverman-Stiglitz (1983a)]. 
(ii) An analysis of the effect of the innovation on the demand for loans is neither necessary nor sufficient to determine the impact of interlinkage on the adoption of innovations. Elsewhere [Braverman-Stiglitz (1982)], we showed that one possible explanation for interlinkage is that, under sharecropping, the amount borrowed affects the landlord's return (through its effect both on the individual's effort and on his decisions concerning choices of technique), and conversely, the terms of the landlord's contract affect the returns to the lender (through its effect on the likelihood of default). Interlinkage was a method by which these 'externalities' could be internalized. But if there are important interactions of the kind just described, then what is of concern to the landlord-cum-lender is the total impact of the innovation on his income; the decomposition of his income into return as a lender, or return as a landlord, has no particular significance. It is clear, however, that the impact of an innovation on a landlord-cum-lender may be quite different from the impact of the same innovation on a landlord who does not control the borrowing activities of his tenants.

We now turn to a more detailed examination of each of these points.

\subsection{The adoption of innovations in interlinked markets}

To ascertain the effect of an innovation on a landlord-cum-lender in an interlinked market, we employ an extension of the simple model developed in section 2 . There, we assumed that the landlord cannot control effort directly, and because tenants receive only a fraction of their marginal product, they will have insufficient incentives for exerting themselves. We assumed that effort was a function of the share they received. ${ }^{22}$ Here, we assume [following Braverman-Stiglitz (1982)] that borrowing too has an effect on effort, while the amount tenants borrow, $B$, will, in turn, be affected by the terms of the loan contract. For simplicity, we shall assume that landlords have only one instrument in the capital market - the rate of interest which they charge on a loan. $^{23}$ Thus, if increased borrowing leads to increased effort, the landlord may attempt to encourage borrowing (by charging a lower interest rate) and conversely, if increased borrowing leads to reduced effort.

We thus write the income of the landlord-cum-lender as

$$
\pi=(1-\alpha) \mathrm{E} f(e, \Omega)+(r-\rho) B
$$

\footnotetext{
${ }^{22}$ Effort is also a function of the plot size, which, for simplicity, we take as fixed for purposes of the present analysis.

${ }^{23}$ In our earlier study, we showed that if the landlord could, he might wish to employ noniinear loan schedules.
} 
and

$$
\begin{aligned}
\frac{\mathrm{d} \pi}{\mathrm{d} \Omega}= & (1-\alpha) \mathrm{E} f_{\Omega}+(1-\alpha) \mathrm{E} f_{e}\left(\frac{\partial e}{\partial \Omega}+\frac{\partial e}{\partial B} \frac{\mathrm{d} B}{\mathrm{~d} \Omega}+\frac{\partial e}{\partial r} \frac{\mathrm{d} r}{\mathrm{~d} \Omega}\right) \\
& +(r-\rho) \frac{\mathrm{d} B}{\mathrm{~d} \Omega}+B \frac{\mathrm{d} r}{\mathrm{~d} \Omega}
\end{aligned}
$$

where

$$
\frac{\mathrm{d} B}{\mathrm{~d} \Omega}=\frac{\partial B}{\partial \Omega}+\frac{\partial B}{\partial r} \frac{\mathrm{d} r}{\mathrm{~d} \Omega}
$$

and where $\rho$ is the opportunity cost of funds to the landlord, $r$ is the rate of interest charged, ${ }^{24}$ and effort, $e$, is viewed as a function of the technology, $\Omega$, the level of indebtedness, $B$, and the rate of interest charged, i.e., $e(\Omega, B, r)$.

The effect of a change in technology now depends on whether the landlord can adjust the interest rate. We start by focusing our remarks on the case where the rate of interest charged is fixed so the terms in $\mathrm{d} r / \mathrm{d} \Omega$ are set at zero. The change in technology has (i) a direct effect, (ii) an indirect effect through an adjustment in effort (which again is ambiguous in sign), and (iii) an indirect effect through an adjustment in the demand for credit. The latter has two distinct effects. First, there is a direct effect, which may be positive or negative, both because the effect on the demand for loans is ambiguous, and because the interest rate charged may be greater or less than the opportunity cost of capital. Secondly, the level of indebtedness has an effect on effort which too is ambiguous in sign; elsewhere we have analyzed the determinants of this effect [Braverman-Stiglitz (1982)].

Because the landlord-cum-lender will always adjust the interest rate he charges so that the total effect (taking into account the adjustment of effort) will be to increase his profits, it is more likely that an innovation will be adopted if the interest rate can be varied than if it cannot. On the other hand contrasting (14) and (5) it is clear that an innovation which increases a landlord's income might lower that of a landlord-cum-lender, and conversely.

Note, in particular that if the rate of interest charged on loans to tenants is the same as the rate of return which they can obtain elsewhere, then, of course, it makes no difference whether the technological innovation leads to

${ }^{24}$ Eq. (13) implicitly assumes the probability of default is zero. More generally, we write

$$
\Pi=(1-\alpha) \mathrm{E} f(e, \Omega)+[\hat{r}(e, \Omega, \beta, r)-\rho] B,
$$

where $\hat{r}$ is the expected return from a loan of size $B$ bearing an interest rate $r$ to individual exerting effort $e$, with technology $\Omega$. Of course, $e$ itself is a function of the terms of the other parameters of the problem. The share $\alpha$ and plot size $T$ also actually affect both effort and the probability of default (and hence $\hat{r}$, given $r$ ) but we take $\alpha$ and $T$ as given, and here suppress the dependence of $\hat{r}$ and $e$ on $\alpha$ and $T$. 
an increase or decrease in borrowing, provided that borrowing does not have an indirect effect on effort. If the tenant borrows from the landlord because he gives him favorable terms (i.e., the terms of the typical tenancy contract do not restrict the tenant's rights to borrow elsewhere) the rate of interest charged by the landlord must be less than or equal to those charged elsewhere, ${ }^{25}$ i.e., $\rho>r$. Hence, though we agree with Bhaduri that a reduction in the demand for loans is a real possibility, the direct effect of this reduction is perhaps as likely to increase landlords' profits as it is to reduce them.

In short, a landlord's incentives for adopting innovations may be enhanced or diminished by interlinking.

Just as before, where we showed that a technological change with observability could shift the utility possibilities curve outward, but with costly monitoring, it chould shift it inward, so too here: with interlinkage, the utilities possibilities schedule might be shifted one way, without it, it could be shifted the other. Interlinking makes it more likely, however, that measured national income will be increased as a result of the adoption of any innovation. In the absence of interlinkage, there is always the possibility that innovations which increase the income of the landlord, at the expense of lenders might be adopted. ${ }^{26}$ Similarly, it is possible that innovations which increase the income of a lender-cum-landlord, decrease the income of landlords in non-interlinked markets, and thus will not be adopted. By internalizing these potential externalities, interlinking may be expected to result in a welfare gain. ${ }^{27}$

\subsection{The determination of tenants' borrowing ${ }^{28}$}

Eq. (14) demonstrates that a critical determinant of the effect of an innovation on the profitability of the landlord-cum-lender was the effect of a change in technology on the demand for borrowing. We asserted that, even for well behaved changes in technology and well behaved utility functions, this could be of either sign. The basic argument is the following.

The objective of borrowing is to smooth income between different periods.

\footnotetext{
${ }^{25}$ This argument is not perfectly persuasive: if landlords are more informed concerning the risk characteristics of their tenants than others, and if the capital market is risk averse, then a tenant who borrows from the open market may have to pay a risk premium. Hence, it is possible that, the opportunity cost for the landlord, $P$, is less than $r$, the rate of interest charged by the landlord, even though $r$ is less than the rate of interest which the tenant can obtain elsewhere.

${ }^{26}$ That is, we now need to expand the utility possibility schedule to include lenders as well as tenants and landlords.

${ }^{27}$ As always, in second best analysis internalizing one set of externalities may exacerbate other inefficiencies.

${ }^{28}$ We are concerned here mainly with borrowing for consumption credit, which as the focus of the Bhaduri-Srinivasan debate. However, Braverman-Stiglitz (1982) present a formulation which points out how the analysis can be extended to cover production credit.
} 
Consider a two period model. If an individual has an abnormally low income in the first period, then he will borrow, in anticipation of having a higher income the next period. (Since there is uncertainty about next period's income, there is, of course, some chance that next period will be even worse than this.) Changes in the distribution of income affect both the likelihood of a low (say below mean) income this period, and the likelihood of that next period; they also have income effects, which affect the individual's willingness to accept different risks. Whether, on average, borrowing will be increased or decreased, depends both on the nature of the change in the probability distribution of output and on the tenant's utility function. ${ }^{29}$ In our working paper [Braverman-Stiglitz (1983a)] we show that a uniform increase in output decreases borrowing if individuals have decreasing absolute risk aversion and the rate of interest exceeds the pure rate of time preference and if the variance of output is small; on the other hand, a mean preserving spread in the distribution of output increases the level of borrowing if the utility function is quadratic but with other plausible utility functions, it may be decreased. The formal procedure by which to analyze the effect of change in technology on the demand for credit is presented in the appendix.

\section{Conclusions}

This paper has shown that there may be some truth in the widespread view that landlords may wish to, and can, resist innovations, changes in technology which increase the amount of output that can be obtained from any given input. The institutional structure of the LDCs may, indeed, be an important determinant of whether a particular innovation is or is not adopted. Although such changes will, under the conventional assumptions concerning costless monitoring of workers, result in an unambiguous outward shift in the utility possibilities schedule, when monitoring is costly and contracts involve some form of sharecropping such innovations may result in segments of the utility possibilities schedule moving inward.

We have also argued that the presence of interlinkages between credit and land markets does not necessarily imply either resistance or encouragement to the adoption of technological innovations. Either case is possible. It might actually encourage the adoption of some technologies which otherwise would not be adopted, even though the effect of this innovation is to reduce tenants' demand for credit. Whether the demand for credit itself is increased or decreased turns out to depend critically both on how the technical change

\footnotetext{
${ }^{29}$ It depends on the value of the first four derivatives of the utility function, as well as on the nature of the change in the distribution of output.
} 
affects the probability distribution of yields and on tenants' utility functions. ${ }^{30}$

The analysis of this paper suggests that the question of the adoption of new technologies is a far more complicated and subtle question than traditional welfare analyses might suggest.

Although we address here the issues of the adoption of innovation within the context of agriculture in a less developed country, it should be clear that very similar issues arise in developed industrialized countries as well. A slight variant of our model can be used to establish that there are certain systematic biases in the nature of the innovations which are adopted; in particular, in Braverman-Stiglitz (1985) we present a simple model which is consistent with the long-standing allegation that capitalism results in the adoption of innovations which entail 'excessive' job routinization.

\section{Appendix}

In this appendix, we show how the effect of a change in technology on the demand for credit can be analyzed. ${ }^{31}$

The individual's borrowing function specifies for each realization of $Y_{1}$ the amount which the individual will borrow,

$$
B=B\left(Y_{1} ; \Omega\right)
$$

The amount borrowed is a function of the individual's income and $\Omega$, some parameterization of the technology, which in turn will determine the probability distribution of $Y_{2}$.

Thus the average amount borrowed is

$$
\bar{B}=\int B\left(Y_{1} ; \Omega\right) \mathrm{d} F\left(Y_{1} ; \Omega\right),
$$

where $F$ is the distribution function of $Y_{1}$. We can now determine how a change in $\Omega$ changes $\bar{B}$, i.e.,

$$
\frac{\mathrm{d} \bar{B}}{\mathrm{~d} \Omega} \sim \int \frac{\partial B}{\partial \Omega} \mathrm{d} F+\int B \mathrm{~d} F_{\Omega}
$$

\footnotetext{
${ }^{30} \mathrm{~A}$ technological innovation such as the introduction of High Yield Varieties (HYV) is often associated not only with higher mean yield but also with higher spread of the distribution, the HYV being more susceptible to bad weather and pests. However, the introduction of HYV is also associated with increase in input of fertilizers and effort, additional 'externalities'. Landlords who internalize all these externalities by interlinking contracts are less likely to resist technological innovations. On the internalization of such externalities through cost sharing arrangements of inputs, see Braverman-Stiglitz (1983b).

${ }^{31}$ For the concepts used here for risk analysis, see Rothschild-Stiglitz (1970).
} 
In Braverman-Stiglitz (1983a) we find conditions under which we can sign $\int B \mathrm{~d} F \Omega$ (how a change in the distribution affects mean borrowing with a given borrowing function) and $\partial B / \partial \Omega$ (how a change in the distribution of $Y$ shifts the borrowing function). $\int B \mathrm{~d} F \Omega$ depends critically on the concavity or convexity of the borrowing function. A mean preserving reduction in variability of $Y_{1}$ decreases the demand for borrowing if the borrowing function is convex while an increase in the mean of $Y_{1}$ will reduce the demand for borrowing. For non-convex borrowing functions the effects may be either convex or concave.

How the innovation affects the probability distribution of $Y_{1}$ is, of course, an empirical question and will vary from innovation to innovation. Often, for instance, the HYV of grain are characterized by both greater mean and greater risk. The shape of the borrowing function, on the other hand, can be related to some simple properties of the individual's utility function. A mean preserving spread in $Y_{2}$ normally leads to reduced borrowing - the greater variability of future income leads individuals to be more conservative if there is decreasing absolute risk aversion.

The total effect of a change in the distribution of $Y$ is obtained by adding the two effects together. Note again that a mean preserving spread in the distribution of $Y_{1}$ increases the demand for credit with a given borrowing function if the borrowing function is convex, but the corresponding change in $Y_{2}$ shifts the borrowing function down: the net effect is ambiguous. We have not found plausible general restrictions in utility functions and/or the admissible changes in distributions, under which the sign of the change in the demand for credit is determinate.

\section{References}

Akerlof, G., 1980, A theory of social custom, of which unemployment may be one consequence, Quarterly Journal of Economics, June.

Alston, H., 1983, Tenure choice in Southern agriculture, Exploration in Economic History 18.

Bardhan, P.K., 1980, Interlocking factor markets and agrarian development: A review of issues, Oxford Economic Papers, March.

Bell, C. and P. Zusman, 1980, On the interrelationship of credit and tenancy contracts (World Bank, Washington, DC).

Bhaduri, A., 1973, Agricultural backwardness under semi-feudalism, Economic Journal.

Bhaduri, A., 1979, Agricultural backwardness under semi-feudalism: A reply, Economic Journal.

Binswanger, Hans P. and Mark R. Rosenzweig, eds., 1984, Contractual arrangements, employment and wages in labor markets in Asia (Yale university Press, New Haven, CT).

Braverman, A. and J.L. Guasch, 1984, Capital requirements, screening and interlinked sharecropping and credit contracts, Journal of Development Economics, April.

Braverman, A. and T.N. Srinivasan, 1981, Credit and sharecropping in agrarian socities, Journal of Development Economics, Dec.

Braverman, A. and J.E. Stiglitz, 1982, Sharecropping and the interlinking of agrarian markets, American Economic Review, Sept.

Braverman, A. and J.E. Stiglitz, 1983a, Landlords, tenants and technological innovations, Working paper (World Bank, Washington, DC) Sept. 
Braverman, A. and J.E. Stiglitz, 1983b, Cost sharing arrangements under sharecropping: Moral hazard, incentive flexibility and risk, Working paper (World Bank, Washington, DC).

Braverman, A. and J.E. Stiglitz, 1985, Unemployment, supervision technology and employers' resistance to technological innovations, Mimeo. (Princeton University, Princeton, NJ).

Hicks, J.R., 1963, Theory of wages (Macmillan, London).

Mitra, P., 1983, A theory of interlinked rural transactions, Journal of Public Economics, March.

Newbery, D.M.G., 1975, Tenurial obstacles to innovations, The Journal of Development Studies, July.

Newbery, D.M.G. and J.E. Stiglitz, 1979, Sharecropping, risk sharing and the importance of imperfect information, ch. 17 in: J.A. Roumasset, J.M. Boussard and I.J. Singh, eds., Risk, uncertainty and agriculture development (Agriculture Development Council, New York) 311340.

Reid, Joseph D., Jr., 1976, White land, black labor and agricultural stagnation, Exploration in Economic History 16.

Rothschild, M. and J.E. Stiglitz, 1970, Increasing risk I: A definition, Journal of Economic Theory 2 .

Rudra, A., 1982, Local power and firm level decision making, Mimeo.

Srinivasan, T.N., 1979, Agricultural backwardness under semi-feudalism - Comment, Economic Journal.

Stiglitz, J.E., 1974, Incentives and risk sharing in sharecropping, Review of Economic Studies. 